\title{
Copulatory behavior and nest building behavior of wild house mice (Mus musculus)
}

\author{
D. Q. ESTEP, D. L. LANIER, and D. A. DEWSBURY \\ University of Florida, Gainesville, Florida 32611
}

\begin{abstract}
The copulatory behavior and nest building behavior of wild house mice (Mus musculus) were examined in an attempt to study the effects of domestication on these behaviors. In the first experiment, 17 male and 17 female wild house mice were observed on a total of 68 tests of copulatory behavior, each carried to a satiety criterion of $90 \mathrm{~min}$ with no intromissions. The basic copulatory pattern was found to be identical to that of domesticated strains of house mice. However, the wild house mice appeared more extreme in certain of the quantitative aspects of copulatory behavior than most inbred strains. In the second experiment, 9 male and 10 female wild house mice and 10 male and 10 female C57BL/6J inbred house mice were tested for nest building behavior for 28 consecutive days. The nest building of wild house mice appeared similar to that of most domesticated house mice, although wild house mice used less cotton in building nests than did domesticated animals.
\end{abstract}

Interest in the effects of domestication on behavior has generated a number of recent studies of wild rodents and comparisons with their domesticated counterparts (e.g., Barnett, 1963; Boice, 1972, 1973; Connor, Winston, \& Bradford, 1973; Plomin \& Manosevitz, 1974; Price, 1972, 1973; Lockard, 1968; Smith, 1972). Few of these studies have emphasized "species-common" behavioral patterns such as copulatory behavior and nest building. If the full effects of domestication are to be assessed, such behavioral patterns should be examined. As even relatively small variations in copulatory patterns can be of considerable importance in the reproductive success of some species (e.g., Adler, 1969), investigations of such patterns are worthy of detailed study. Nest building behavior in small mammals probably is of survival value in the natural habit as an aid to thermoregulation (Dawson \& Lang, 1973; Lynch, 1974; Lynch \& Hegmann, 1972).

In light of the possibility that these behavioral patterns may have undergone change as a result of domestication, detailed studies of copulation and nest building in wild populations seem warranted. The present report provides detailed quantitative data on the copulatory behavior and nest building behavior of wild house mice, Mus musculus, and compares such behaviors with those of inbred strains.

\section{EXPERIMENT I: COPULATORY BEHAVIOR}

The existence of quantitative differences in copulatory behavior among inbred strains of Mus musculus has been established by a number of investigators (Levine, Barsel, \& Diakow, 1966; McGill,

Portions of this work were submitted by D. Q. Entep in partial fulfiliment of the requirements for the desree of Master of Art at the University of Florida. Hormones were provided through the courtesy of the Schering Corporation, Bloomfield. New Jersey. This research was supported by Grant GB-33837X from the National Science Foundation. Please send requests for reprints to D. Q. Estep, Department of Psycholosy, University of Florida, Gainesville, Florida 32611.
1962, 1970; McGill \& Blight, 1963; McGill \& Ransom 1968; Vale \& Ray, 1972; Wilson, 1968). Our first experiment was conducted to provide the first such quantitative data on wild-trapped house mice, as well as a a more detailed description of the behaviors accompanying copulation. The added detail afforded by such categorizations facilitates cross-species comparisons (Dewsbury, 1972b). In the comparative study of behavior such detailed behavioral descriptions are essential for the development of behavioral taxonomies just as detailed morphological descriptions are essential in comparative anatomy.

\section{Method}

Subjects. The subjects were 17 male and 17 female wild Mus musculus, live-trapped in Sherman traps over a 4-month period from April to August, 1972. The subjects were collected from two dog kennels located on the University of Florida Animal Research Farm near Gainesville, Florida. The location is approximately $3.2 \mathrm{~km}$ from the Psychology Building and the nearest possible source of domesticated house mice. In over 2 years of breeding in the laboratory, all animals were found to breed true for the wild type coat color. Such facts make it unlikely that these animals were descended from or contaminated by escaped domesticated Mus musculus. All subjects had been adapted to the laboratory environment for at least 4 weeks prior to behavioral testing and all were adults when tested.

Mice were housed in isolation in clear plastic cages measuring $29 \times 19 \times 13 \mathrm{~cm}$. The bottoms of the cages were lined with a commercially produced liner material, San-i-cel, and contained commercial bedding material, "Nestlets" (Ancare Corp.). All animals received Purina Lab Chow and water ad lib.

Apparatus. All behavioral tests were conducted in clear Plexiglas cylinders $60 \mathrm{~cm}$ high and $38 \mathrm{~cm}$ in diam. Behavioral patterns were recorded on an Esterline-Angus event recorder.

Procedure. The colony room was maintained on a reversed 14:10 light-dark cycle of white fluorescent light with two dim 25-W red light bulbs shining at all times. The dark phase, during which the white fluorescent lights were off, occurred between 0900 and $1900 \mathrm{~h}$. Behavioral testing was carried out approximately at the midpoint of the dark phase.

Females were brought into behavioral estrus with sequential injections of estradiol benzoate and progesterone following the 
Table 1

Definitions of the Standard Measures of Copulatory Behavior

ML Mount latency. The time in seconds from the introduction of the female to the first mount.

IL Intromission latency. The time in seconds from the introduction of the female until the male gains intromission.

PEI Postejaculatory interval. The time in seconds from the end of the ejaculation duration of one series to the beginning of the first intromission of the next series.

MF Mount frequency. The number of mounts without intromission per series.

TM Time of mount. The number of seconds from the beginning of a mount without intromission until the male dismounts.

IF Intromission frequency. The number of intromissions preceding ejaculation in each series.

PIMD Preintromission mount duration. The number of seconds from the beginning of a mount with intromission until the first thrust of intromission.

TI Time of intromission. The number of seconds from the beginning of a mount with intromission until the male dismounts. .

III Interintromission interval. The time in seconds from the end of one intromission to the beginning of the next.

Th/I Thrusts per intromission. The number of thrusts in each intromission.

Tot Th Total thrusts. The total number of thrusts given in each series.

EL . Ejaculation latency. The time in seconds from the start of the first intromission to the start of the ejaculation duration of each series.

ED Ejaculation duration. The number of seconds the male spends clutching the female and maintaining vaginal contact following each ejaculation.

\#HM Number of head mounts. The number of times the male mounts the female's head per series.

Root The number of seconds the male spends rooting under the female.

\%Move Percentage move. The percentage of time after an intromission that the male moves away from the female before he starts to groom.

\%Bite Percentage bite. The percentage of time the male bites the female following an ejaculation.

MFR Mean female receptivity. Mean overall receptivity score for each test based on receptivity scores for each intromission. The system employs a 5-point scale with a score of 5 indicating high receptivity.

procedures of McGill (1962). Behavioral testing began 5 to $8 \mathrm{~h}$ after the progesterone injection.

Tests were conducted in the colony room with the two red 25-W bulbs which normally illuminated the colony room plus one other $25-W$ red bulb placed near the testing cylinders. The males were placed in the Plexiglas cylinders from 1-2 h before testing to allow for adaptation to the surroundings. Tests began with the introduction of the female. If no intromission occurred within 90 min after the introduction of the female, the test was terminated. If copulation was initiated, testing continued until $90 \mathrm{~min}$ had elapsed since the last intromission. Each male was tested with the same female partner on all tests. Tests were conducted at 2-week intervals until each pair had a total of six positive tests or five consecutive negative tests.

\section{Measures}

The copulatory behavior of Mus musculus consists of a group or "series" of mounts without vaginal penetration (mounts), mounts with vaginal penetration (intromissions), and mounts with intromission and ejaculation (ejaculations) (McGill, 1962). The measures of copulatory behavior employed here included 16 measures used by McGill (1962) plus measures of female receptivity (MFR) and the intervals between copulatory series (PEI). These measures are defined in Table 1.

Categorization of the behaviors accompanying copulation was also made for both males and females of each pair. While the standard measures of copulatory behavior were scored on all positive tests, the behaviors accompanying copulation were categorized on only one test for each male and each female of a pair. The male categorization was generally made on the fifth positive test for a given pair of animals, the female categorization on the sixth positive test. Categorization was initiated at the start of the test and terminated $30 \mathrm{~min}$ after ejaculation. The mutually exclusive behavior categories were adapted from those of Dewsbury $(1967,1970,1971,1972 a, 1973)$. Several of these measures were defined in the same manner as those used by Dewsbury (1973, p. 189). Those measures were sitting still (equivalent to Dewsbury's "standing still"), general groom self, genital groom self, locomotor exploratory, pursuit (seen in males only), approach resistant female (males only), upright defense (equivalent to Dewsbury's "sparring," seen in females only), run from male (females only), and lordosis (females only). In addition, five other categories were distinguished. They were:

General Groom Partner - Scratching, licking, or manipulating the other animal on areas of the body other than the anogenital region.

Genital Groom Partner - Scratching, licking, manipulating, or sniffing the anogenital region of the partner.

Sniffing Partner - Where the animal has approached the partner, orients toward it, and appears to sniff it in area of the body other than the anogenital region.

Root - Active pushing or lifting the partner with the head.

Groomed or Rooted - Inactive and rather plastic posture assumed when partner is grooming or rooting.

Mounting (males only) - Mounting, intromitting, or ejaculating by males.

\section{Results and Discussion}

The basic motor patterns for wild house mice were essentially identical to those described by McGill (1962) for inbred house mice. The pattern consisted of a number of mounts and intromissions distributed in time and culminating in ejaculation. Upon mounting, the male palpated the female's sides and made numerous rapid shallow pelvic thrusts. When vaginal penetration had been achieved the thrust rate became slower and more regular. The number of intravaginal thrusts per intromission was variable. Ejaculation occurred after a variable number of intromissions. During the ejaculatory intromission, the vaginal thrusting increased in rate, then the male clutched the female tightly with all four paws, shuddered strongly, and then usually fell to his side, dragging the female with him. Both animals remained immobile in this position for about $25 \mathrm{sec}$ with the male maintaining vaginal penetration during this time. Following mounts, intromissions, and ejaculations both the male and female generally engaged in genital grooming of themselves. Biting of the female following 
ejaculations, a behavior pattern observed in some inbred strains (McGill, 1962), was not observed in this group of wild Mus musculus.

Highly receptive females showed lordotic postures in response to mounting by males. They raised their heads and tails, forming inverted arches in their backs. They would generally hold this posture until the males dismounted. While this posture was shown by highly receptive females, it was not essential for successful intromission. Both males and females displayed rooting behavior, as described in previous studies (McGill, 1962), although the instances of females rooting males were found to be infrequent. In about $20 \%$ of the tests ( 13 of $68)$ a second copulatory series with ejaculation occurred.

The quantitative results of the standard measures of copulatory behavior for wild Mus musculus are presented in Table 2. Data for the first ejaculatory series are based upon a total of 68 tests from 12 pairs of wild Mus musculus (Range: 4-6 tests per pair). The data are presented as both medians and means with standard errors of the mean to allow comparisons with data from previous studies. Data for the second copulatory series were from only 13 tests with 5 pairs of animals.

Inspection of the medians presented in Table 2 indicates that it takes about $10 \mathrm{~min}$ from the start of the test for wild Mus to initiate copulation. On the average, males had no mounts, and about 7 intromissions each lasting $11 \mathrm{sec}$ and spaced about $2 \mathrm{~min}$ apart. The males required about 135 total thrusts to ejaculation. Mean female receptivity was 3.1. For males showing a second series there were, on the average, no mounts, and fewer intromissions that were slightly shorter but with longer IIIs than in the first series. Fewer total thrusts preceded ejaculation.

Categorizations of the behavior associated with copulation were completed for 9 pairs of animals. Death of one partner prevented categorization for 3 pairs. The data collected from the behavioral categorizations are expressed as the percent of the total time engaged in each mutually exclusive category in each of the three time periods. These periods were further divided into quarters. The intromission latency period (ILP) was defined as the time from the start of the test to the start of the first intromission. The ejaculation latency period (ELP) was defined as the time from the first intromission to the end of the ejaculation duration. The satiety period (SP) was defined as the period from the end of the ejaculation duration until $30 \mathrm{~min}$ had elapsed from that ejaculation or to the start of the first intromission of the second series.

Presented in Figures 1 and 2 are the data for males and females, respectively. As these figures show, both males and females spent the majority of their time in the ILP and SP engaged in locomotor-exploratory behavior. During the ELP, males spent about $25 \%$ of their time mounting the females. The rest of the ELP was about evenly distributed in the activities of genital and general grooming self, sitting, and locomotor-exploratory behavior. Females during the ELP spent about $30 \%$ of their time engaged in lordosis and less than $10 \%$ of their time running from males or in the upright defense posture. Almost $40 \%$ of the time, the females were engaged in sitting, genital and general grooming self, or being groomed and rooted.

The results of the present study indicate that there are no qualitative differences between this particular population of wild Mus and the domesticated Mus studied to date with regard to the basic motor patterns of copulatory behavior. However, quantitative comparisons seem warranted. Such comparisons must be

Table 2

Median, Mean, and Standard Error of 18 Measures of Copulatory Behavior

\begin{tabular}{|c|c|c|c|c|c|c|}
\hline \multirow[b]{2}{*}{ Measures* } & \multicolumn{2}{|c|}{ Median } & \multicolumn{2}{|c|}{ Mean } & \multicolumn{2}{|c|}{ Standard Error } \\
\hline & Series 1 & Series 2 & Series 1 & Series 2 & Series 1 & Series 2 \\
\hline ML & 617.7 & & 774.4 & & 110.49 & \\
\hline IL & 631.5 & & 813.4 & & 102.36 & \\
\hline PEI & & 1650.0 & & 2255.0 & & 359.5 \\
\hline MF & 0 & 0 & 2.5 & .3 & 1.60 & .17 \\
\hline $\mathrm{TM}$ & 0 & 0 & 1.3 & .4 & .45 & .25 \\
\hline IF & 7.3 & 4.5 & 12.5 & 6.4 & 3.38 & 3.45 \\
\hline PIMD & 1.0 & 1.0 & 1.3 & 1.2 & .10 & .11 \\
\hline TI & 11.0 & 9.0 & 14.5 & 10.8 & 1.48 & 1.59 \\
\hline III & 135.0 & 220.0 & 146.7 & 300.2 & 16.26 & 86.76 \\
\hline $\mathrm{Th} / \mathrm{I}$ & 20.5 & 13.5 & 22.2 & 16.2 & 2.46 & 4.45 \\
\hline Tot Th & 138.8 & 80.0 & 190.1 & 73.4 & 35.52 & 5.60 \\
\hline EL & 886.8 & 1257.0 & 1483.1 & 1142.5 & 337.42 & 291.67 \\
\hline ED & 25.8 & 17.0 & 24.9 & 17.8 & 2.26 & 2.90 \\
\hline \#HM & 0 & 0 & 1.0 & .8 & .30 & .31 \\
\hline Root & 10.3 & 0 & 30.7 & 8.4 & 12.01 & 6.76 \\
\hline \%Move & 71.6 & 61.5 & 63.8 & 67.8 & 6.28 & 13.17 \\
\hline$\%$ Bite & 0 & 0 & 0 & 0 & 0 & 0 \\
\hline MFR & 3.1 & 3.3 & 3.1 & 3.0 & .22 & .44 \\
\hline
\end{tabular}

*Time measures are expressed in seconds. 
Figure 1. Categorization of male copulatory behavior. Each measure is expressed as percent of total time for each quarter of each time period. ILP Intromission latency period. ELP Ejaculation latency period. SP - Satiety period. Time periods are defined in text.

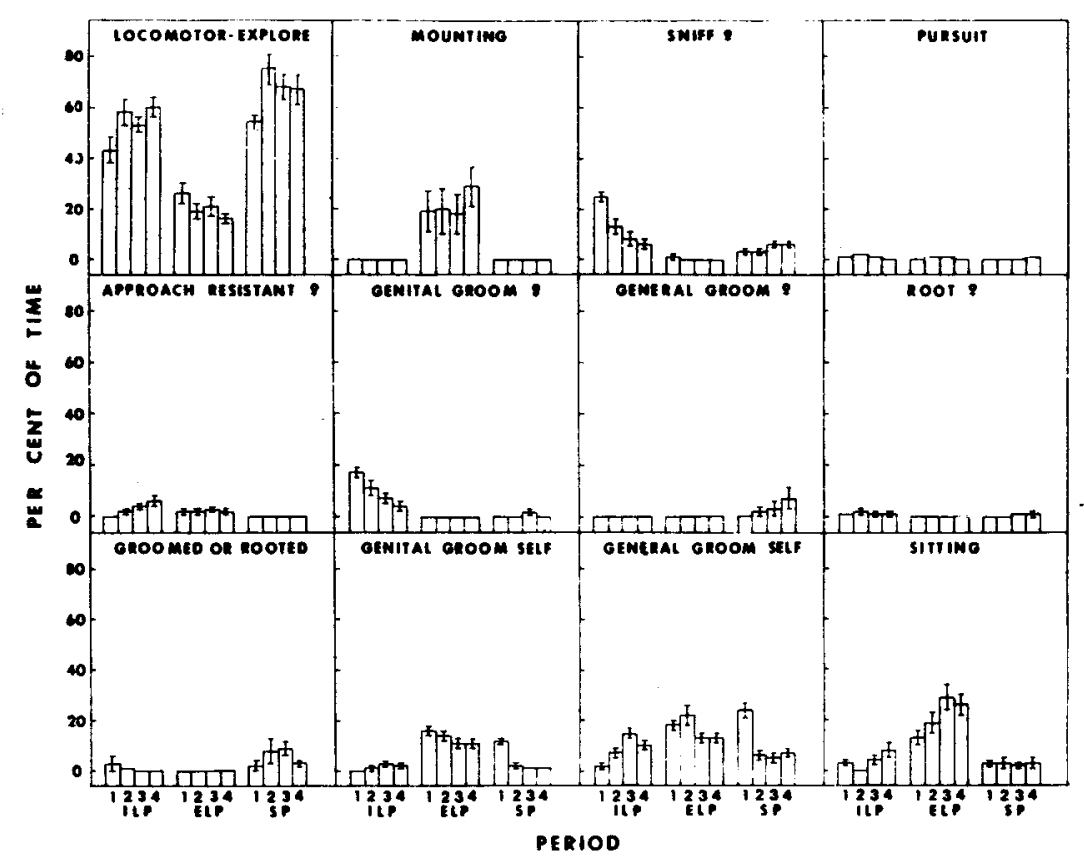

interpreted with caution, as they are based on tests conducted in different laboratories at different times. However, as testing conditions were generally similar, these comparisons permit a general indication of the behavior of the present wild population in relation to that of inb red strains.

Five studies were chosen for comparison with the present data because of close correspondence in procedures, methods of analysis, and measures (McGill, 1962, 1970; McGill \& Blight, 1963; McGill \& Ransom, 1968; and Vale \& Ray, 1972). The only major procedural differences among these five studies and the present one concerned the criteria for inclusion of data.
Vale and Ray included data only from tests in which the male initiated copulation within $30 \mathrm{~min}$ or less. McGill and his colleagues, in their four studies, included data only from tests where the males initiated copulation in 10-15 $\mathrm{min}$ or less and where females had receptivity scores of 3.0 or greater. In the present study all tests were used regardless of female receptivity scores. Intromission latencies of up to 90 min were permitted. Application of the criteria of Vale and Ray to the present data would not have affected the quantitative measures reported in Table 2. Application of the criteria of McGill would affect only 3 of 15 measures where comparisons were possible (IF, EL, III). The other three
Figure 2. Categorization of female copulatory behavior. Each measure is exprewed as percent of total time for each quarter of each time period. ILP Intromision htency period. ELP Ejaculation latency period. SP - Satiety period. Time periods are defined in text.

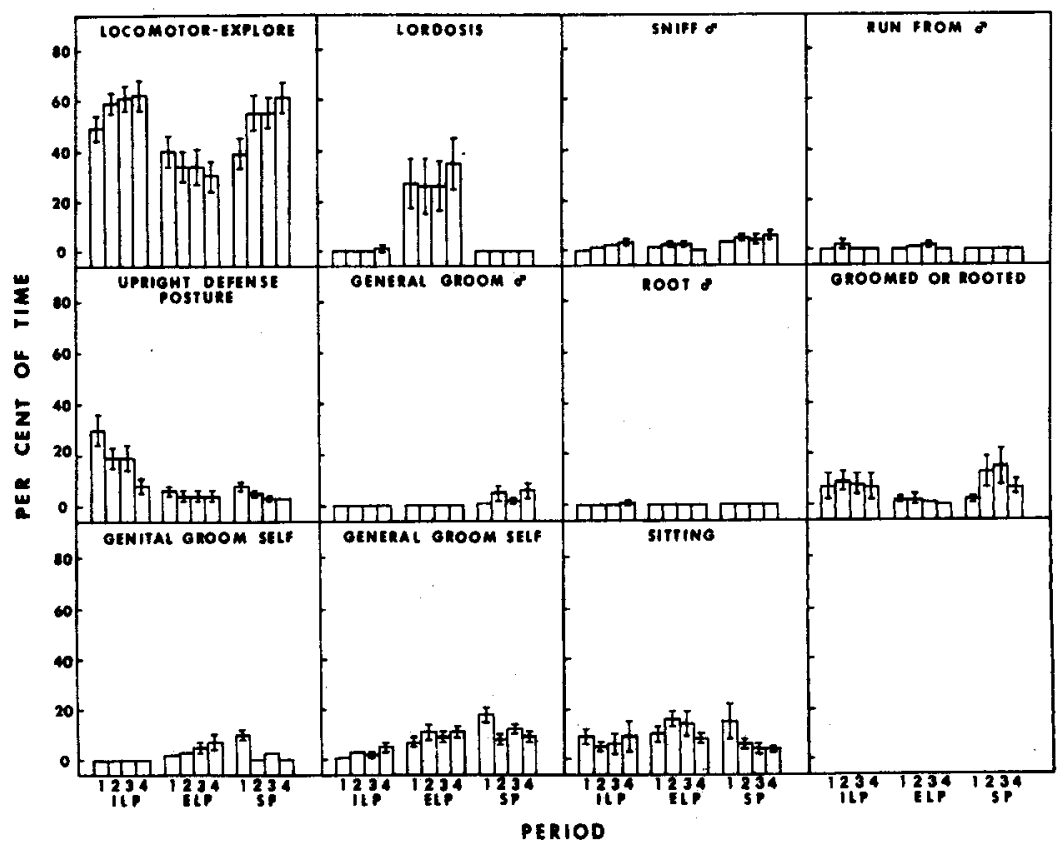


measures in Table 2, ML, IL, and MFR, were the criteria used to distinguish between the two groups, and, of course, comparisons among these measures are impossible.

Figure 3 compares the quantitative data from those from inbred genotypes from the five selected studies on six measures. Means from the present study were only compared with data from studies reporting means; medians from the present study compared only with data presented in studies reporting medians. A general trend appears evident in that wild Mus score at or near the extremes of the range of scores for the inbreds on most measures. For example, with regard to MF, wild Mus fall outside the range of means and medians reported for inbred genotypes. Similarly, for the measures Tot Th and IL, the wild Mus fall at or near the extremes of the ranges. For the measures EL and IF, comparisons of the overall means and medians of the present data with the data of Vale and Ray show the wild Mus to be somewhat intermediate among the scores of the inbreds. Comparisons of the data from McGill with the present data meeting his criteria show the wild Mus to be at or near the lower extremes of the ranges for these same two measures. The present data meeting the criteria of McGill for the measure III and the overall means and medians for the same measure both seem to fall near the midrange for inbreds.

A ranking of means and medians of wild Mus against means and medians from all genotypes (hybrids plus inbreds) studied in these five studies for the same six measures revealed similar trends. Wild Mus rank at or near the extremes of the ranges of means and medians for these genoty pes with respect to HM, PIMD, TI, ED, $\mathrm{TH} / \mathrm{I}$, and ML.

McGill and his colleagues did not report any measures of variability in any experiment discussed here. However, Vale and Ray reported standard deviations for all their measures. Comparisons among the standard errors of the mean reported here and with those derived from the standard deviations of Vale and Ray allow some assessment of the differences in variability between inbred and wild Mus. On five of 10 measures compared (ML, IL, EL, ED, and TI) the wild Mus were more variable than all other genotypes. They were more variable than most other genotypes on two other measures (IF and III), intermediate on the measure Tot Th, and less variable than most genotypes on MF and $\mathrm{HM}$.

In summary, then, wild Mus have longer latencies to initiate copulation than do most domesticated strains. Once started, however, wild Mus show fewer mounts, fewer intromissions to ejaculation, fewer total thrusts to ejaculation, and longer intervals between intromissions. They also show a longer ejaculation duration and fewer head mounts during copulation. Wild Mus also tend to be more variable than domesticated Mus on most measures of copulation.

\section{EXPERIMENT II: NEST BUILDING BEHA VIOR}

Although there have been reports on nest building behavior in inbred strains of house mice (e.g., Lee, 1973; Lee \& Wong, 1970; Lisk, Pretlow, \& Friedman, 1969; Lynch \& Hegmann, 1972, 1973), there have been few reports of nest building in wild house mice. The present experiment provides such a report. To provide a baseline for comparison of data from this laboratory to those from other laboratories, animals of a frequently used inbred strain, $\mathrm{C} 57 \mathrm{BL} / 6 \mathrm{~J}$, were also studied.

\section{Methods}

Subjects. The subjects were 9 male and 10 female laboratory-reared offspring of wild trapped Mus musculus and 10

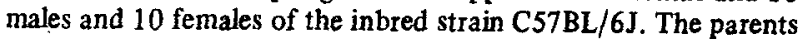
of the wild animals were trapped in the same dog kennels near Gainesville, Florida as were the subjects in Experiment I. The C $57 \mathrm{BL} / 6 \mathrm{~J}$ subjects were purchased from the Jackson Laboratories, Bar Harbor, Maine. All of the subjects were between 60 and 180 days of age at the start of testing. Prior to the start of testing, all subjects were housed and maintained in the same manner as the subjects in Experiment I.

Apparatus. Unbleached cotton batting was used as nesting material. Tests were conducted in an air conditioned room maintained on a reversed 14-h light, 10-h dark cycle with light onset at 1900 h. Nest building was tested in the animals'
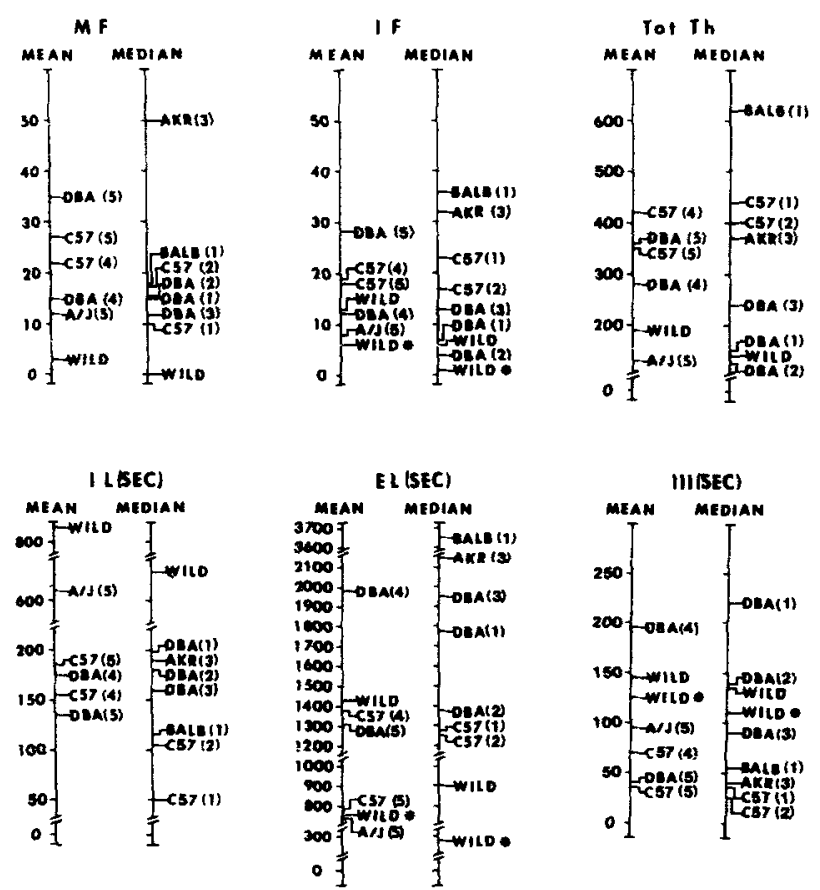

Figure 3. Comparison of present data with means and medinns from five other studies for six selected measures. Measures are defined in text. IL, EL, and III are expressed in seconds. Each series of letters followed by a number in parentheses refers to a particular strain studied in one of these five studies: (1) MoGill, 1962; (2) McGill and Blight, 1963; (3) McGill and Ransom, 1968; (4) MaGill, 1970; (5) Vale and Ray, 1972. WILD - Data from all subjects in present study. WLL* - Data from only those subjects that meet the criteria of McGill. 
Table 3

Mean Cotton Pulled (Grams) Daily and Body Weights (Grams) for Males and Females of Two Genotypes of House Mice

\begin{tabular}{|c|c|c|c|c|c|c|c|}
\hline \multirow[b]{2}{*}{ Sex } & \multirow[b]{2}{*}{ Measure } & \multicolumn{4}{|c|}{$\begin{array}{c}\text { Cotton Pulled (g) } \\
\text { Week }\end{array}$} & \multicolumn{2}{|r|}{$\begin{array}{c}\text { Body } \\
\text { Weight }\end{array}$} \\
\hline & & 1 & 2 & 3 & 4 & $\overline{\mathbf{X}}$ & (g) \\
\hline
\end{tabular}

Wild

\begin{tabular}{clrrrrrr} 
& Mean & 3.65 & 2.55 & 3.20 & 3.98 & 3.3 & 18.8 \\
Males & SE & .55 & .51 & .52 & .58 & .5 & 1.2 \\
& Mean & 3.91 & 3.94 & 3.95 & 5.41 & 4.3 & 15.6 \\
Females & SE & .85 & .99 & .92 & 1.2 & .9 & .9 \\
C57BL/6J & & & & & & & \\
& Mean & 4.44 & 4.37 & 5.41 & 5.03 & 4.8 & 23.2 \\
Males & SE & .88 & .85 & .98 & .65 & .8 & .2 \\
& Mean & 6.18 & 5.90 & 6.84 & 5.92 & 6.2 & 19.3 \\
Females & SE & .72 & .52 & .63 & .61 & .5 & .3 \\
\hline
\end{tabular}

home cages. The temperature of the room was continuously monitored and found to remain at $24^{\circ} \mathrm{C} \pm 1^{\circ} \mathrm{C}$ during the entire testing period.

Procedure. On the first day of testing, animals were weighed to the nearest $0.1 \mathrm{~g}$. Food was removed from the food hopper of the cage and was placed on the floor of the cage. Cotton batting was then cut into strips and placed in the food hopper. Then the cage top and cotton batting were weighed to the nearest $0.1 \mathrm{~g}$. Twenty-four hours later the cage top and remaining cotton batting were again weighed. The difference in the weight between the first and second days provided a measure of the amount of cotton pulled by the animal for the preceding $24 \mathrm{~h}$. Several characteristics of the nest built were recorded and the nest was removed from the cage. If necessary, more cotton was placed on the cage lid and it was reweighed. This procedure was repeated daily for 28 consecutive days.

Measures. In addition to determining the amount of cotton pulled daily, nests were classified into the following categories:

Type 1. No nest - Cotton may have been pulled but no obvious nest was constructed.

Type 2. Platform nest - A pallet of cotton on the floor used for nesting but with no sides or cover.

Type 3. Bowl-shaped nest - A bowl or cup-shaped nest with sides, either with or without a bottom and without a cover.

Type 4. Covered nest - A bowl or cup-shaped nest with sides and a cover. These nests may or may not have a bottom.

\section{Results and Discussion}

Table 3 presents the mean amounts of cotton used (pulled) daily in grams for males and females of both genotypes over the 28 -day testing period. The data are presented in four weekly blocks. Mean body weights in grams are also presented. An analysis of variance on the amounts of cotton used indicated a significant difference between genotypes $(F=5.58$, df $=1 / 35, p<.025)$. The inbred mice used significantly more cotton over days than did the wild mice. There were no significant sex differences. There were significant overall differences among the four one-week periods $(F=3.48, \mathrm{df}=3 / 105$, $p<.025)$. However, trend analyses using orthogonal polynomials (Hays, 1963; Winer, 1971) revealed no simple linear or quadratic trends in the data for any group over weeks. A significant interaction of Genotype by Week was found $(F=3.25, \mathrm{df}=3 / 105, \mathrm{p}<.025)$.
The chi-square tests performed on the nest-type data revealed that covered nests (Type 4) were the most frequently built by males and females of both genotypes $\left(x^{2}=69.25, \mathrm{df}=1\right.$ for $\mathrm{C} 57 \mathrm{BL} / 6 \mathrm{~J}$ males; $\mathrm{x}^{2}=76.17$, $\mathrm{df}=1$ for C57BL/6J females; $\mathrm{x}^{2}=46.17 \mathrm{df}=1$ for wild males; $x^{2}=50.50, \mathrm{df}=1$ for wild females; $p<.001$ in all cases). However, significant strain differences occurred in the frequency with which no nest (Type 1) was built and with which covered nests (Type 4) were built $\left(\mathrm{x}^{2}=119.06, \mathrm{df}=1, \mathrm{p}<.001\right.$ for Type 1, $\mathrm{x}^{2}=29.09, \mathrm{df}=1, \mathrm{p}<.001$ for Type 4). Wild Mus built no nest more frequently than did C57BL/6J mice while the inbreds built covered nests more frequently than did the wild mice.

The present data indicate significant differences between these genotypes with regard to the amounts of cotton used daily and in the relative frequencies with which different nest types were built. There were no sex differences in the amounts of cotton used and there appear to be no simple trends over days in the amounts of cotton used by any group.

Figure 4 graphically presents comparisons of the present data with data reported for inbred strains in three other studies (Lee \& Wong, 1970; Lynch \& Hegmann, 1972, 1973). These studies were chosen for comparison because of the close similarities in
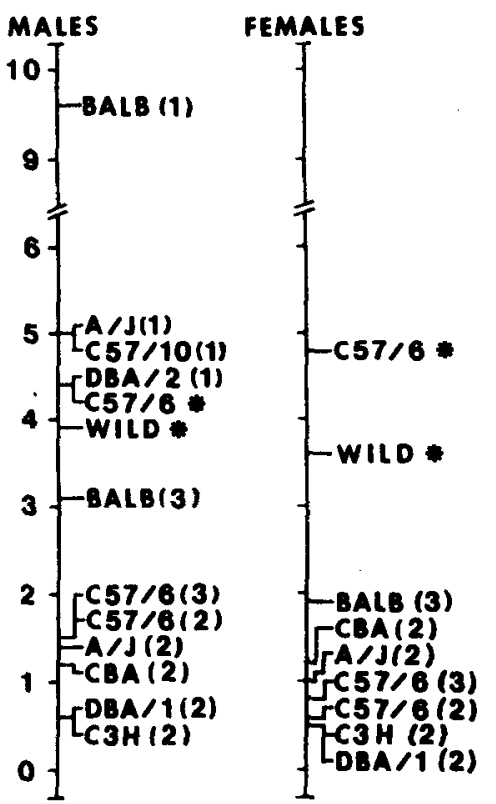

Figure 4. Comparison of mean daily cotton use for first four days of testing between wild and inbred Mus musculus from present study with inbred mice from five other studies. Each series of letters followed by a number in parentheses refers to a particular strain used in one of these studies. BALB - BALB/cJ, $A / J-A / J, C 57 / 10$ - C57BL/10J, C57/6 - C57BL/6J, C3H C3H/HeJ, CBA - CBA/J, DBA/1 - DBA/IJ, DBA/2 - DBA/2J. The studies were (1) Lee and Wong, 1970; (2) Lynch and Hegmann, 1972; (3) Lynch and Hegmann, 1973; * Dats from the present study. Data from Lee and Wong are estimates from the data presented in their Figure $1(1970$, p. 9) for the first 4-day block at $25^{\circ} \mathrm{C}$ 
procedures, temperatures at testing, and nesting materials used. Data collected by Plomin and Manosevitz (1974) on several populations of wild Mus were not compared to the present data because of several procedural differences between the two studies. All of the data compared in Figure 4 represent daily mean nesting scores for the first 4 days of testing at temperatures ranging from $24^{\circ} \mathrm{C}$ to $26^{\circ} \mathrm{C}$. Inspection of the figure reveals that the present data for male wild $\mathrm{Mus}$ musculus fall well within the range of scores for inbreds reported by Lee and Wong (1970). However, the present data for both wild and inbred animals are consistently higher than the data reported by Lynch and Hegmann (1972, 1973). Such differences among studies for similar genotypes (C57BL/10J for Lee and Wong, 1970; C57BL/6J for Lynch and Hegmann, 1972, 1973, and the present study) suggest important differences in maintenance or testing procedures.

In that the present data for wild Mus musculus fall within the range of scores of inbreds from at least one other study, our data suggest that no major changes in nest building behavior have occurred in house mice as a result of domestication, at least as measured by the amount of cotton used daily and the general type of nest built. Further research comparing other inbred strains and other wild populations at different ambient temperatures may reveal important differences among wild and domesticated genotypes not seen here. Lynch and Hegmann (1973), for example, find that different inbred strains react differently in their nest building to the same temperature changes.

In that significant differences in nest building have been shown to exist among inbred strains of house mice (Lee, 1972, 1973; Lee \& Wong, 1970; Lynch \& Hegmann, 1972, 1973) and among different populations of wild house mice (Plomin \& Manosevitz, 1974) comparisons should be made to a wide variety of wild and domesticated genotypes to assure the validity of any generalizations.

Comparisons of nest type data can be made among the present data and data reported by Lisk et al. (1969) for an unspecified strain of mice given hay as nesting material and Lee (1972) using C57BL/6J mice given cotton batting. Lisk et al. and Lee both report the most frequently built nests to have sides but no cover equivalent to a Type 3 nest in the present study. Both wild and inbred Mus in the present study built covered nests (Type 4) most frequently. These differences may be due to differences in the testing and/or housing procedures or to differences in the nesting materials given the animals.

Two other comparisons should be mentioned at this point. The lack of significant trends in cotton use over weeks in the present data is in contrast to data collected by Lee (1972). Lee found the inbred strains he studied to show a significant linear increase in cotton use over weeks. The differences in these results may be explained by age differences in the animals at the time of testing (60-210 days of age for the present animals, 30-60 days for the animals used by Lee). The lack of significant sex differences in cotton use among the animals reported here is in agreement with data collected on inbred house mice by Lisk et al. (1969) and by Lee (1972), but are in contrast to the significant sex differences reported by Lee (1973) and by Lynch and Hegmann $(1972,1973)$. No explanation can be given for these conflicting data at the present time.

In summary, the present data suggest some differences between wild and domesticated house mice with regard to nest building behavior, although the differences do not appear to indicate that substantial changes have occurred in this behavior as a result of domestication. The differences reported across laboratories for the same inbred strains seem to indicate important uncontrolled environmental variables operating on this behavior as it is currently measured.

\section{GENERAL DISCUSSION}

The present results indicate that although there are some differences between wild and inbred Mus musculus in their copulatory and nest building behaviors, the overall patterns of these behaviors are identical in both genotypes. The data suggest that no major qualitative changes have occurred in inbred Mus musculus as a result of domestication with regard to these behaviors.

However, the present data also suggest that certain quantitative changes in these behaviors may have occurred as a result of domestication. Wild Mus musculus may be more extreme than many domesticated strains with regard to several measures of copulatory behavior. Wild Mus appear to achieve ejaculation with fewer mounts, intromissions, and thrusts than most domesticated strains, but wild Mus have longer intromission latencies, longer intervals between intromissions, and longer ejaculation durations than most domesticated strains. If this result proves to be of some generality, the differences between wild and inbred Mus could be due to changes occurring during domestication of the inbred Mus. Shifts in the selective pressures operating on the genes controlling these behaviors during domestication would remove certain genes from the gene pool. Such selection against the faster inbred Mus could explain these differences. Another equally likely explanation for these differences involves inbreeding depression. Bruell (1964) has argued that characters related to reproductive fitness of an organism are sensitive to inbreeding. Such characters tend to show a depression or decrease in the population mean when compared to the population means for wild genotypes.

If differences between wild and inbred genotypes in the variability of the copulatory measures also proves to be a general finding, these differences could also be 
partially explained by changes due to domestication. Removal of certain extreme genotypes from the gene pool of the inbred Mus could reduce the genetic variance of the inbreds and thus reduce the phenotypic variance. Alternatively, the process of inbreeding itself could be responsible for the reduction in variability of these measures. Fixation of alleles at specific loci in the genome of inbred genotypes would reduce the genetic variance within inbred strains of Mus and produce increased phenoty pic uniformity in these measures.

Generalizations about the quantitative differences in nest building behavior between wild and inbred Mus are best left until further research clarifies the reasons for the wide variability in these measures as reported by different laboratories. Until the quantitative aspects of nest building can be adequately replicated in different laboratories for the same genotypes, generalizations about differences between genotypes seem premature.

Since all of the domesticated Mus discussed here have also been inbred, it is impossible at this point to determine the relative effects of domestication and inbreeding on this species. Investigations comparing various wild populations with non-inbred domesticated and inbred domesticated strains are needed to clarify the relative effects of these two different processes on the behavior of this species. Furthermore, several wild populations of this species should be compared. As recently demonstrated by Plomin and Manosevitz (1974), considerable behavioral polytypism can occur among different wild populations of Mus musculus even for such "species-common" behaviors as nest building and open field activity. Such data emphasize the point that there is no such thing as the wild population of Mus musculus. This fact must be taken into account before any meaningful conclusions can be drawn about the effects of domestication on any behavior in any species.

\section{REFERENCES}

Adler, N. T. Effects of the male's copulatory behavior on successful pregnancy of the female rat. Journal of Comparative and Physiological Psycholozy, 1969, 69. 613-622.

Bamett, S. A. The nat: A study in behaviour. Chicago: Aldine, 1963.

Boice, $R$. Some behavioral tests of domestication in Norway rats. Behavoiur, 1972, 42, 198-231.

Boice, R. Domestication. Psychological Bulletin, 1973, 80, 215-230.

Bruell, J. H. Inheritance of behavioral and physiological characters of mice and the problem of heterosis. American Zoologist, 1964, 4, 125-138.

Connor, J. L.. Winston, H. D., \& Bradford, H. The effects of domestication, environmental familiarity and opponent familiarity on dominance in the mouse (Mus musculus $L$.) Behavior Genetics, 1973, 3, 339-354.
Dawson, G. A., \& Lang. J. W. The functional significance of nest building by a neotropical rodent (Sigmodon hispidus) American Midland Naturalist, 1973, 89, 503-509.

Dewsbury, D. A. A quantitative description of the bebavior of rats during copulation. Behaviour, 1967, 29, 154-178.

Dewsbury, D. A. Copulatory behavior of rice rats (Oryzomys palustris). Animal Behaviour, 1970, 18, 266-275.

Dewstoury, D. A. Copulatory behavior of old-field mice (Peromyacus polionotus subgriseus). Animal Behaviour, 1971, 19, 192-204.

Dewsoury, D. A. Copulatory behavior of cotton rats (Sigmodion hisp idus). Zeitschrift für Tierpsychologie, 1972, 30,477-487. (a)

Dewsbury, D. A. Patterns of copulatory behavior in male mammals. Quarterly Review of Biology, 1972, 47, 1-33. (b)

Dewsbury, D. A. Copulatory behavior of montane voles (Microtus montanus). Behaviour, 1973, 44, 186-202.

Hays, W. L. Statistics for psychologists. New York: Holt, Rinehart, \& Winston, 1963.

Lee, C. T. The development of nest building behavior in inbred mice. Joumal of General Psy chology, 1972, 87, 13-21.

Lee, C. T. Genetic analysés of nest building behavior in laboratory mice (Mus musculus). Behavior Genetics, 1973, 3 , 247-256.

Lee, C. T., \& Wong, P. T. P. Temperature effect and strain differences in the nest building behavior of inbred mice. Psychonomic Science, 1970, 20, 9-10.

Levine, L.. Barsel, G. E., \& Diakow, C. A. Mating behavior of two inbred strains of mice. Animal Behaviour, 1966, 14, 1-6.

Lisk, R. D. Pretlow, R. A., III, \& Friedman, S. M. Hormonal stimulation necessary for elicitation of maternal nest building in the mouse (Mus musculus). Animal Behaviour, 1969, 17, $730-737$.

Lockard, R. B. The albino rat: A defensible choice or a bad habit. American Psy chologist, 1968, 23, 734-742.

Lynch, C. B. Environmental modification of nest building in the white footed mouse, Peromy scus leucopus. Animal Beh aviour, $1974,22,405-409$

Lynch, C. B., \& Hegmann, J. P. Genetic differences influencing behavioral temperature regulation in small mammals. I. Nesting by Mus musculus. Behavior Genetics, 1972, 2, 43-53.

Lynch, C. B., \& Hegmann, J. P. Genetic differences in fluencing behavioral temperature regulation in small mammals. II. Genoty peenvironment interactions. Behavior Genetics, 1973 . 3, 145-154.

McGill, T. E. Sexual behavior in three inbred strains of mice. Behaviour, 1962, 19,341.350.

McGill, T. E. Genetic analysis of male sexual behavior. In Lindzey, G., \& Thiessen, D, D. (Eds.), Contributions to behavior-genetic analysis: The mouse as a prototype. New York: Appleton-Century-Crofts, 1970, 57-88.

McGill, T. E., \& Blight, W. C. The sexual behavior of hybrid male mice compared with the sexual behavior of males of the inbred parent strains. Animal Behaviour, 1963, 11, 480-483.

McGil, T. E., \& Ransom, T. W. Genoty pic change affecting conclusions regarding the mode of inheritance of elements of behavior. . Animal Behaviour, 1968, 16, 88-91.

Plomin, R. J., \& Manosevitz, M. Behavioral polyt ypism in wild $M$ us musculus. Behavior Genetics, 1974, 4, 145-157.

Price, E. O. Novelty-induced self-food deprivation in wild and semidomestic deer mice (Peromyscus maniculatus bairdi). Behaviour, 1972, 41, 91-104.

Price, E. O. Some behavioral differences between wild and domesticated Norway rats: Gnawing and platform jumping. Animal Learning \& Behavior, 1973, 1, 312-316.

Smith, R. H. Wildness and domestication in Mus musculus. A behavioral analysis. Joumal of Comparative and Phy giological Psy chology, 1972, 79, 22-29.

Vale, J. R., \& Ray, D. A diallel analysis of male mouse sex behavior. Behavior Genetics, 1972, 2, 199-209.

Wilson, J. R. A. Effects of components of the sexual behavior pattern of male laboratory mice upon maintenance of pregnancy in female mice. PhD Dissertation, University of California, Berkeley, 1968, University Microfilms. Ann Arbor, Michigan. (Dissertation Abstracts, 68, 13969).

Winer, B. J. Statistical principles in experimental design. New York: McGraw-Hill, 1971.

(Received for publication November 12, 1974 Revision accepted May $13,1975$. 